\title{
Conceptual validation of an innovative remote pulmonary rehabilitation solution for Chronic Obstructive Pulmonary Disease
}

\author{
Andrea Méndez, $\mathrm{PhD}^{1,2}$, Patricio Labra, Licentiate ${ }^{3}$, Juan Pablo Guerrero, Master ${ }^{4}$, Carlos Nieto, Licentiate ${ }^{1,2}$, \\ Bárbara Martínez, Master ${ }^{1,2}$, Gonzalo Hidalgo, Licentiate ${ }^{1,2,5}$, Iván Rodríguez-Núñez, PhD ${ }^{6}$
}

\begin{abstract}
A Méndez, P Labra, JP Guerrero, C Nieto, B Martínez, G Hidalgo, I Rodríguez-Núñez. Conceptual validation of an innovative remote pulmonary rehabilitation solution for Chronic Obstructive Pulmonary Disease. Can J Respir Ther 2021;57:121-125. doi: 10.29390/cjrt-2021-025.

Introduction: Chronic Obstructive Pulmonary Disease (COPD) is the third leading cause of death in the world. Pulmonary rehabilitation (PR) reduces COPD hospitalisations, although its use is low. Telerehabilitation is effective; however, in Chile the development of remote PR technology is incipient. Therefore, the aim of the study was to validate conceptual aspects of an innovative remote PR solution for COPD.

Methods: This mixed study used a nonprobabilistic sample of PR professionals and people with COPD (PwCOPD) from Santiago. The perception of a conceptual solution for PR through a semi-structured interview was determined. Professionals were also asked about willingness to use technology using a questionnaire designed and validated in 75 professionals in this study. The study was approved by the Ethics Committee and data were collected after informed consent.

Results: Twenty-two participants were recruited, of which 14 were professionals and eight were PwCOPD. Among professionals and patients, the willingness to use the solution is positive because it would reduce visits and improve self-management, although it should include a remote/in-person combination, training, and user-friendly interface. Most of the professionals were willing to use technology for pulmonary rehabilitation.

Conclusions: The development of telehealth technologies should consider the expectations of patients and professionals and may incorporate elements of persuasive technologies in the design. The results could contribute to the development of digital solutions for remote PR in PwCOPD.
\end{abstract}

Key Words: telerehabilitation; validation study; innovative therapy; physical rehabilitation medicine; Chronic Obstructive Pulmonary Disease

\section{INTRODUCTION}

Chronic Obstructive Pulmonary Disease (COPD) is a lung condition with systemic manifestations that impairs the quality of life [1]. It is the third leading cause of death in the world [2]. Its prevalence is $4 \%-10 \%$ worldwide [3] and $16.9 \%$ in Chile [4]. It is currently considered a major public health problem globally [5].

It has been shown that pulmonary rehabilitation (PR) improves exercise tolerance, peripheral muscle function, quality of life, and reduces hospitalizations [6, 7]; however, this treatment strategy is not widely used. The frequency of patients admitted for PR varies between $1.2 \%$ in Canada and $6 \%$ in the United Kingdom [8, 9]. Also, $40 \%-60 \%$ of patients complete therapy according to studies from the United Kingdom [7, 9]. In Chile, patients admitted to PR represent $2.4 \%-2.9 \%$ of all COPD patients, and the frequency of completion is $26 \%-36 \%$ [10]. Therefore, the need to develop and investigate new models of more accessible and acceptable PR has been identified [11].

Lung telerehabilitation has shown equivalent effectiveness to face-toface PR in exercise capacity [12-15], respiratory symptoms, anxiety and depression, and quality of life, with greater adherence in conventional
PR $[13,15]$. One study reported the superiority of telerehabilitation versus face-to-face PR on respiratory symptoms and anxiety and depression [14]. Also, higher levels of self-management, high levels of patient and companion satisfaction, and low frequency and severity of adverse events have been reported with pulmonary telerehabilitation [16-21].

Several types of platforms have been developed for telerehabilitation. The most widely used have been videoconferencing software [14, 16-23], and web platforms and smartphone applications (App) [12, 13, 24, 25]. However, only videoconferencing platforms have been implemented in Chile. There is no reported software design for telerehabilitation. Therefore, this study set out to validate the conceptual aspects of an innovative remote pulmonary rehabilitation solution for people with COPD (PwCOPD).

Study design

\section{METHODS}

A convergent, parallel mixed-methods study was designed and approved, for May 2019 to March 2020, by the Scientific Research Ethics Committee of the Universidad Central de Chile with code 14/2019. All participants provided written informed consent.

\footnotetext{
${ }^{1}$ Escuela de Kinesiología, Facultad de Salud y Ciencias Sociales, Campus Providencia, Sede Santiago, Universidad de las Américas, Santiago, Chile

${ }^{2}$ Centro de Investigación e Innovación Biopsicosocial en Enfermedades Crónicas, Facultad de Salud y Ciencias Sociales, Universidad de las Américas, Santiago, Chile

${ }^{3}$ Centro de Salud Familiar Alberto Bachelet Martinez, Corporación Municipal de Salud de Conchali, Santiago, Chile

${ }^{4}$ Escuela de Tecnología Médica, Facultad de Ciencias de la Salud, Universidad Central de Chile

${ }^{5}$ Hospital de niños Dr. Luis Calvo Mackenna

${ }^{6}$ Departamento de Kinesiología, Universidad de Concepción, Concepción, Chile

Correspondence: Andrea Méndez, Escuela de Kinesiología, Facultad de Salud y Ciencias Sociales, Campus Providencia, Sede Santiago, Universidad de las Américas, Santiago, Chile. Address: Manuel Montt 948, Santiago, Chile. Post code: 7500975. Phone: 22531710. E-mail: mmendezg@udla.cl
}

Published online at https://www.cjrt.ca on 18 August 2021

This open-access article is distributed under the terms of the Creative Commons Attribution Non-Commercial License (CC BY-NC) (http:// creativecommons.org/licenses/by-nc/4.0/), which permits reuse, distribution and reproduction of the article, provided that the original work is properly cited and the reuse is restricted to noncommercial purposes. For commercial reuse, contact editor@csrt.com 


\section{Participants}

Participants included professionals who were part of an outpatient PR team and PwCOPD in control in primary care centres in the western area of Santiago. The inclusion criteria for professionals were to be a Physiotherapist, to be a permanent member of an outpatient PR team, or to have worked in PR in any region of the country. Professionals who were members of a hospital PR team were excluded. Inclusion criteria for users (PwCOPD) were older than 40 years, with a diagnosis of stage I to IV COPD, and who understood Spanish. Users with an inability to give informed consent or to understand questions were excluded.

Additionally, to validate the questionnaire on willingness to use technology in health care, a population composed of physiotherapists was defined. The inclusion criteria were to work in any area of physiotherapy, in any of the regions of the country. Participants reporting a different profession, or two professions, were excluded.

A nonprobability convenience sample was obtained from primary care centres, hospitals, and universities in different regions for professionals, and from the Dr. Raúl Yazigi primary care centre for users. The sample obtained for instrument validation was nonprobabilistic by convenience, from different regions of the country.

\section{Conceptual solution}

We created a service that seeks to facilitate access of PwCOPD to the rehabilitation programme using remote PR, carried out through an App to be installed on mobile devices. This App supports the programme through exercise instructions, educational aspects, feedback with clinical information and motivational elements such as rewards or gamification, as well as elements that enable communication between a user and a professional and among users. The information provided about the App was limited to obtain broad responses from the interviewees.

\section{Variables}

In the health professionals group the primary outcome was "perception of the conceptual solution" that was determined through a semi-structured interview, using a grid of questions: (i) What works about the proposal? (ii) What could be improved? (iii) What questions arise? (iv) What new ideas emerge? The secondary outcome in the health professionals group was the willingness to use health technologies that was determined using a self-administered questionnaire, designed based on the consumer context of use construct (UTAUT2) [26]. This was constructed with 10 questions, each with 5 alternative answers on a Likert scale (Suppl 1) ${ }^{1}$. The result was expressed as "Willing" or "Not Willing." To obtain this result, each question was scored from 1 to 5 points, using an inverted scale for negative questions. The sum of scoring was in a range from 10 to 50 points. Less than 35 points was considered "Not Willing," and 36 points or above was considered "Willing." The questionnaire was validated on a pilot basis as part of the current study in the previously mentioned sample. The professionals were characterised by gender, age, years of experience and region.

In PwCOPD the primary outcome was "perception of the conceptual solution" through a semi-structured interview, using the grid of questions and structure previously indicated. PwCOPDs were characterised by gender and age.

\section{Data collection}

Data were collected between May 2019 and March 2020. Subjects were invited to participate, and professionals obtained permission from the administration of their institution.

After recruitment, semi-structured interviews were conducted individually by the investigators C.N. and B.M., face-to-face, in the absence of others, for 35-40 min, and were audio-recorded. The interviews with professionals were conducted at the respective workplaces, and the interviews with PwCOPD were conducted at the health centre.

To validate the instrument the data collection was carried out through social networks. After inviting participants, a link was provided

\footnotetext{
${ }^{1}$ Supplementary files are available at: https://www.cjrt.ca/wp-content/ uploads/Supplement-cjrt-2021-025.docx
}

to access the questionnaire. This form was disseminated on social networks three times, in consecutive weeks.

\section{Statistical analysis}

Quantitative variables were described by the median and interquartile range and qualitative variables by proportions. The validity of the questionnaire on willingness to use technology in health care was determined by internal reliability with Cronbach's alpha. The analysis was carried out in STATA software (version 14.2, StataCorp).

The processing of material from the interviews to determine the perception of the solution was carried out in the hermeneutic analysis software Atlas Ti 9.0, which made it possible to structure a corpus of data through coding that facilitated the elaboration of categories and the recognition of relationships between them. First, the data were open coded, then the codes were revised as the analysis progressed, and categories were defined to communicate the results. The analysis used a sequential scheme based on the constant comparison of data and progressive incorporation of new informants until the categories were saturated. Results were analysed by two researchers, independent from each other, using the same methodology, to triangulate information and reduce interpretation bias.

\section{Recruitment and characteristics}

Twenty-two participants were recruited: 14 professionals and eight PwCOPD, who met the inclusion criteria.

The health professionals group was $50 \%$ female $(n=7)$, with a median age of 37 years (interquartile range 33-39 years), a median of 13 years of experience (interquartile range $9-14$ years), and $78.57 \%(n=11)$ from the Metropolitan Region (Table 1). PwCOPD were $62.5 \%$ female $(n=5)$, with a median age of 71 years (interquartile range $65-75.5$ years) (Table 1).

\section{Perception of the conceptual solution}

Thirteen professionals and eight PwCOPD were interviewed. One professional declined to be interviewed. The results obtained were organised into three categories:

\section{1) Willingness to use telerehabilitation tools}

Professionals: The willingness to use eHealth tools is positive, especially because of the possibility of improving access to intervention. They perceive it as a complement to face-to-face PR, which allows PR continuity throughout the year, even in periods of high demand for care or administrative overload. However, they recognise some obstacles to its use: the financial investment required for low-income users, inadequate mobile phone equipment, and the need for remote monitoring or self-monitoring systems for users with comorbidities. They recognise that the legal implications of risky situations for the health of users, while they are undergoing treatment, should be considered.

I find the idea interesting. I think it could benefit a part of the popu-
lation, solving access problems. In my place of work, patients from
rural areas have great difficulty in getting to the CESFAM [Centro de

TABLE 1

Characterization of lung rehabilitation professionals and people with COPD

\begin{tabular}{lcc}
\hline Demographics & Professional & People with COPD \\
\hline Sex, $n(\%)$ & & \\
Female & $7(50)$ & $5(62.5)$ \\
Male & $7(50)$ & $3(37.5)$ \\
Age (years), median (RI) & $37(33-39)$ & $71(65-75.5)$ \\
Years of experience, median (RI) & $13(9-14)$ & - \\
Region, $n(\%)$ & & - \\
$\quad$ Metropolitan & $11(78.57)$ & - \\
Another & $3(21.43)$ & - \\
\hline
\end{tabular}

$\mathrm{RI}=$ interquartile range; $\mathrm{COPD}=$ Chronic Obstructive Pulmonary Disease. 
Salud Familiar (Family Health Centre)] which is why the vast majority could not enter pulmonary rehabilitation. [...] Costs associated with mobilisation were beyond their means and the CESFAM does not have resources for mobilisation. On the other hand, for some patients who can handle the technology that you indicate to me, it would be beneficial as it would allow constant control and reinforcement with them, making sure that they carry out the indications to obtain the expected results (E1002, p. 18).

PwCOPD: The main consideration is that there should be a pre-use assessment by the practitioner and then alternate face-to-face and remote activities. In general, the idea of the App is favourable; however, people recognise differences according to the age group to which they belong, previous employment, and experience with technology, e.g., social networks, video games, or others. Therefore, respondents noted they would require: training, a user-friendly and interactive interface, availability of a mobile device with data coverage, and equipment at home to carry out the exercises.

It could be alternated, one day in the CESFAM another in the application, as some people do want to walk to get there and others who do not, so it should be mixed, with the option of both [...] It should have a previous course on how to use the application, and not underestimate older adults if they teach us, we learn (E2002, p. 22).

\section{2) Perception of the benefit of the proposed App}

Professionals: They point out that it would favour self-management and the incorporation of healthy habits. Also, the App would make it possible to reduce the frequency of visits, reducing contagion without discontinuing PR and favouring adherence and user follow-up.

The continuity of treatment because sometimes a person with COPD who has compromised activities of daily living, in the displacement, in short, going to the CESFAM can be complicated, then have it at home [...] and if it is an application that has everything clear [...]. How to use it and that the Physiotherapist also helped them with education, I think that could favour treatment adherence, that is the main idea. Financially it also helps the state because it is not going to have Physiotherapist-patient or Physiotherapist-with the group with COPD [...] face-to-face (E1013, p. 22).

Mainly adherence to the exercises, to give them more continuity, to be able to know if the patients actually [perform the] exercises, it is very different to call them on the phone, to an application that I can monitor the exercise a little bit, that they can put I don't know, the BORG [(Borg Test) ...] I can see, rather than with the pulse, which is perhaps something more complex for them [...] if they executed the task or not (E1011, p. 7).

PwCOPD: It would avoid transfers to the centre, reducing expenses, difficulties due to mobility limitations, and the need to have a companion. It would allow them to make it compatible with their current work activity by not having to go to the health centre, or because of waiting times, as they could do PR from home, with no time limit. Also, they point out the possibility of being monitored by the professional in charge of their treatment, remembering the indications, and having educational material about their illness at home.

It would be very favourable for my job because I am a taxi driver [...] so, I can't go around, you could say, wasting time at the clinic. I hardly came today, even though my wife got me, she got me together with her to see me more quickly because I race at 3 o'clock, so there was a change in the timetable. So, you see, I look favourably on that. It's not that the person bothers me, you know what I mean? (E2004, p. 4).

3) Identification of the tools and resources that the App should incorporate to favour its use and the achievement of results

Professionals: It should contemplate a friendly design for the elderly population or with those unexperienced with the use of technology, favouring a personalised treatment. It must have user-oriented training for the user and any caregivers. It should allow for the gradual delivery of indications according to the degree of compliance with the PR. To this end, it is important to provide feedback, incorporating reminders of activities to favour adherence as well as resources that visualise achievements and maintain motivation. Also, it should allow communication between professionals and users, reporting incidents or doubts. They see it as an additional alternative to the possibility of incorporating resources for interaction and group communication among users through the use of forums or information from existing community networks.
It should be a customisable, didactic, motivating, transversal applica- tion by related ages, and should be controlled remotely by a Physiotherapist online, trying to be more motivating for participants who have never done pulmonary rehabilitation [...] more than a friendly application, that is empathetic with the user without overvalu- ing anything or anyone (E1008, p. 4).
What I do think would be very important too, and what generates more adherence in a working group [...] is to generate networks. At least as a very personal opinion, the best form of adherence is when links are generated between users, when they go and meet and greet each other, they generate wellbeing, because first, they disconnect a little from the world, they leave their work schedule, they leave their problems at home, and that generates instances of socialisation, and they generate adherence because they go to a place to exercise and they go to mobilise (E1010, p. 7).

PwCOPD: The design should be user-friendly and encourage interaction in its use, with detailed instructions in clear language. Having channels of communication with the professional, in case of doubts or emergencies during or outside the centre's working day, would allow them to take appropriate measures, for example, to know how to act during a crisis, contributing to the perception of safety in its use. In this way, they identify the use of mobile video call applications or WhatsApp as a resource. It should include monitoring and favour the correction of errors during PR, especially in the execution of exercises, favouring personalised compliance. They recognise the need for motivational elements that allow them to visualise and identify their progress and achievements and to consider the existence of users who are not very motivated or resistant to behavioural change.

\begin{abstract}
How will they know that the exercise is for me and that I do it well, will the Physiotherapist see me in the first instance, or will I start the programme immediately? (E2003, p. 31).
\end{abstract}

Yes, because you also say, I could have a heart attack, what do I do, or what do I do with the person who is having one, so it is good to know what to do in these cases (E2008, p. 22).

A system of exercises in which one can do breathing and all that to manage it at home in free moments (E2007, p. 18).

Willingness to use technology in health care

The pilot validation of the questionnaire on willingness to use technology in health care was carried out on 75 physiotherapists in the current study. The results showed an internal reliability coefficient of 0.8739 .

Out of a total of 14 professionals recruited, 13 responded to the questionnaire "Willingness to Use Technologies in Health Care". A total of $69.23 \%(n=9)$ reported being willing to use technologies (Figure 1).

\section{DISCUSSION}

This study shows that the willingness of professionals and patients to use an App is positive, because it would reduce visits and improve selfmanagement, although it should include a combination of remote faceto-face intervention, training, and a user-friendly interface.

The development and implementation of telehealth technologies should consider critical strategies, including understanding patient and 


\section{FIGURE 1}

Willingness to use technologies in health care. The percentage frequency of individuals in relation to their willingness to use health technologies, in the categories "willing" and "unwilling" is shown.

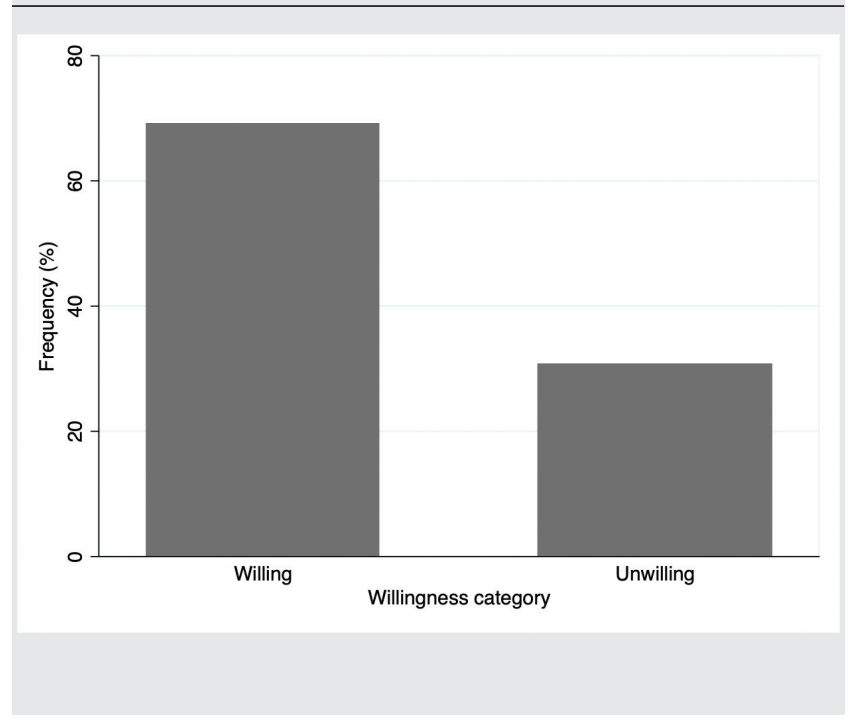

provider expectations [27], addressing the domains of quality of care (safe, effective, patient-centred, timely, efficient and equitable) [28], and elements of persuasive technologies (PT), designed to bring about behavioural and attitudinal changes $[29,30]$.

Patient-centred care can improve the outcomes that patients want so that health care is responsive to the individual [28]. The design of any solution should consider the perceptions not only of PwCOPD but also of professionals.

Expectations of the professionals must be understood in the context of complex face-to-face care because of the time required and, the need for records, among others, so that there is a growing interest in using efficient and accurate technological innovations whose information is easily integrated with medical records. In patients, these expectations are linked to the impact that the internet has had on obtaining health information [27]. The findings on perceptions of the App show a scenario where professionals do not provide frequent PR due to overburdened care or administrative workload, and PwCOPD have barriers to access. The App is seen as a complementary tool to face-to-face PR, and PwCOPD need to continue to perceive the professional as someone close to them who provides personalised treatment and is concerned about patient progress and compliance.

The use of PT in the design of Apps can help with treatment compliance [31, 32]. Professionals pointed out that the App would favour self-management and the incorporation of healthy habits, as well as encourage adherence and follow-up. However, practitioners and PwCOPD expressed the need for a user-friendly and interactive interface for older adults, detailed instructions, and clear language. Therefore, elements of persuasive technologies can be used in the design of health technologies, such as gamification elements, visual and auditory rewards, and feedback (self-monitoring, feedback, and reward strategies) [33]. Persuasive socially oriented strategies (competition and comparison) [29], such as messaging among users, could also encourage behavioural adoption.

Safety is a key factor in care [28]. Professionals pointed out the need for monitoring systems in users with comorbidity, and PwCOPD indicated the need for communication channels with the professional in case of doubts or emergencies, in addition to receiving correction in the execution of exercises. Thus, innovative health solutions should incorporate these aspects.

Technology use, according to the unified theory of acceptance and use of technology (UTAUT), depends on performance expectancy, effort expectancy, social influence, facilitating conditions, hedonic motivation, price and habit, which are moderated by age, gender, and experience (UTAUT2) [26]. It has been reported that in professionals perceived usefulness is a predictor of telerehabilitation use [34], and in patients affordability and accessibility are facilitators for using telerehabilitation [34].

Although a low sample was obtained, the responses made it possible to identify the perceptions and willingness to use technologies in a subgroup of patients and professionals which is small. Also, the validity results suggest the potential usefulness of this tool.

\section{CONCLUSIONS}

The results will enable the development of an App for remote PR based on the Chilean Ministry of Health's clinical guidelines. The App could facilitate access of COPD users to PR, aiming to reduce decompensation, improve treatment outcomes, and reduce costs, with a public health perspective and incorporating management tools. In addition, although the sample was small, the results could contribute to understanding the perception of solutions Apps for telerehabilitation in professionals and patients, and to know the willingness to use technologies in health care, which may be useful in the design of future digital solutions.

\section{DISCLOSURES}

\section{Acknowledgments}

We thank the director of the Dr. Raúl Yazigi Family Health Centre for allowing and facilitating the development of this study, and Ignacio Silva for collaborating in the data collection.

\section{Contributors}

All authors were responsible for (i) substantial contributions to the conception and design of the work; and the acquisition, analysis, and interpretation of data for the work; (ii) drafting the work and revising it critically for important intellectual content; (iii) final approval of the version to be published; and (iv) agreement to be accountable for all aspects of the work in ensuring that questions related to the accuracy or integrity of any part of the work are appropriately investigated and resolved. All authors read and approved the final version of the manuscript.

\section{Funding}

This study did not receive any specific grant from funding agencies in the public, commercial or not-for-profit sectors.

\section{Competing interest}

All authors have completed the ICMJE uniform disclosure form at www. icmje.org/coi_disclosure.pdf and declare: no financial relationships with any organizations that might have an interest in the submitted work in the previous 3 years; no other relationships or activities that could appear to have influenced the submitted work.

\section{Ethical approval}

Informed consent was obtained from all participants. The Scientific Research Ethics Committee of the Universidad Central de Chile approved the study.

\section{REFERENCES}

1. McGuinness A, Sapey E. Oxidative stress in COPD: sources, markers, and potential mechanisms. J Clin Med 2017;6(2):21.

2. Lozano R, Naghavi M, Foreman K, Lim S, Shibuya K, Aboyans V, et al. Global and regional mortality from 235 causes of death for 20 age groups in 1990 and 2010: a systematic analysis for the Global Burden of Disease Study 2010. The Lancet 2012;380(9859):2095-128.

3. Halbert RJ, Isonaka S, George D, Iqbal A. Interpreting COPD prevalence estimates: what is the true burden of disease? Chest 2003;123(5):1684-92.

4. Menezes AMB, Perez-Padilla R, Jardim JB, et al. Chronic Obstructive Pulmonary Disease in five Latin American cities (the PLATINO study): a prevalence study. The Lancet 2005;366(9500):1875-81.

5. López-Campos JL, Tan W, Soriano JB. Global burden of COPD. Respirology 2016;21(1):14-23. 
6. Di Marco F, Santus P, Sotgiu G, Blasi F, Centanni S. Does improving exercise capacity and daily activity represent the holistic perspective of a new COPD approach? COPD J Chronic Obstr Pulm Dis 2015;12(5):575-81.

7. Hogg L, Garrod R, Thornton H, McDonnell L, Bellas H, White P. Effectiveness, attendance, and completion of an integrated, system-wide pulmonary rehabilitation service for COPD: prospective observational study. COPD J Chronic Obstr Pulm Dis 2012;9(5):546-54.

8. Brooks D, Sottana R, Bell B, et al. Characterization of pulmonary rehabilitation programs in Canada in 2005. Can Respir J 2007;14(2):87-92.

9. Moore E, Newson R, Joshi M, et al. Effects of pulmonary rehabilitation on exacerbation number and severity in people with COPD. Chest 2017;152(6):1188-202.

10. Méndez A, Labra P, Pizarro R, Baeza N. Low rates of participation and completion of pulmonary rehabilitation in patients with Chronic Obstructive Pulmonary Disease in primary health care. Rev Médica Chile 2018;146(11):1304-8.

11. Rochester CL, Vogiatzis I, Holland AE, et al. An official American Thoracic Society/European Respiratory Society policy statement: enhancing implementation, use, and delivery of pulmonary rehabilitation. Am J Respir Crit Care Med 2015;192(11):1373-86.

12. Bourne S, DeVos R, North M, et al. Online versus face-to-face pulmonary rehabilitation for patients with Chronic Obstructive Pulmonary Disease: randomised controlled trial. BMJ Open 2017;7(7):e014580.

13. Chaplin E, Hewitt S, Apps L, et al. Interactive web-based pulmonary rehabilitation programme: a randomised controlled feasibility trial. BMJ Open 2017;7(3):e013682.

14. Hansen H, Bieler T, Beyer N, et al. Supervised pulmonary tele-rehabilitation versus pulmonary rehabilitation in severe COPD: a randomised multicentre trial. Thorax 2020;75(5):413-21.

15. Holland AE, Mahal A, Hill CJ, et al. Home-based rehabilitation for COPD using minimal resources: a randomised, controlled equivalence trial. Thorax 2017;72(1):57-65.

16. Burkow TM, Vognild LK, Johnsen E, et al. Comprehensive pulmonary rehabilitation in home-based online groups: a mixed method pilot study in COPD. BMC Res Notes 2015;8:766.

17. Holland AE, Hill CJ, Rochford P, et al. Telerehabilitation for people with Chronic Obstructive Pulmonary Disease: feasibility of a simple, real time model of supervised exercise training. J Telemed Telecare 2013;19(4):222-6.

18. Marquis N, Larivée P, Saey D, Dubois MF, Tousignant M. In-home pulmonary telerehabilitation for patients with Chronic Obstructive Pulmonary Disease: a pre-experimental study on effectiveness, satisfaction, and adherence. Telemed E-Health 2015;21(11):870-9.

19. Paneroni M, Colombo F, Papalia A, et al. Is telerehabilitation a safe and viable option for patients with COPD? A feasibility study. COPD J Chronic Obstr Pulm Dis 2015;12(2):217-25.

20. Tsai LLY, McNamara RJ, Dennis SM, et al. Satisfaction and experience with a supervised home-based real-time videoconferencing telerehabilitation exercise program in people with Chronic Obstructive Pulmonary Disease (COPD). Int J Telerehabilitation 2016;8(2):27-38.

21. Tsai LLY, McNamara RJ, Moddel C, Alison JA, McKenzie DK, McKeough ZJ. Home-based telerehabilitation via real-time videoconferencing improves endurance exercise capacity in patients with COPD: the randomized controlled TeleR study: telerehabilitation in patients with COPD. Respirology 2017;22(4):699-707.

22. Simonÿ C, Riber C, Bodtger U, Birkelund R. Striving for confidence and satisfaction in everyday life with Chronic Obstructive Pulmonary Disease: rationale and content of the tele-rehabilitation Programme >C @ $\odot$ PD-Life >. Int J Environ Res Public Health 2019;16(18):3320.

23. Tousignant $\mathrm{M}$, Marquis $\mathrm{N}$, Pagé $\mathrm{C}$, et al. In-home telerehabilitation for older persons with Chronic Obstructive Pulmonary Disease: a pilot study. Int J Telerehabilitation 2012;4(1):15-24.

24. Marshall A, Medvedev O, Antonov A. Use of a smartphone for improved self-management of pulmonary rehabilitation. Int J Telemed Appl 2008;2008:1-5.

25. Rassouli F, Boutellier D, Duss J, Huber S, Brutsche MH. Digitalizing multidisciplinary pulmonary rehabilitation in COPD with a smartphone application: an international observational pilot study. Int J Chron Obstruct Pulmon Dis 2018;13:3831-6.

26. Venkatesh V, Thong J, Xu X. Consumer acceptance and use of information technology: extending the unified theory of acceptance and use of technology. MIS Q 2012;36(1):157.

27. Schwamm LH. Telehealth: seven strategies to successfully implement disruptive technology and transform health care. Health Aff (Millwood) 2014;33(2):200-6

28. Institute of Medicine (US) Committee on Quality of Health Care in America. Crossing the quality chasm: a new health system for the 21st century. Washington, DC: National Academies Press; 2001 [cited 2020 Nov 6]. p. 337. Available from: http://www.nap.edu/catalog/10027

29. Orji R, Oyibo K, Lomotey RK, Orji FA. Socially-driven persuasive health intervention design: competition, social comparison, and cooperation. Health Informatics J 2019;25(4):1451-84.

30. Orji R, Moffatt K. Persuasive technology for health and wellness: state-ofthe-art and emerging trends. Health Informatics J 2018;24(1):66-91.

31. Oyibo K, Orji R, Vassileva J. Developing culturally relevant design guidelines for encouraging physical activity: a social cognitive theory perspective. J Healthc Inform Res 2018;2(4):319-52.

32. Oyibo K, Vassileva J. Investigation of persuasive system design predictors of competitive behavior in fitness application: a mixed-method approach. Digit Health 2019;5:205520761987860.

33. Orji R, Reilly D, Oyibo K, Orji FA. Deconstructing persuasiveness of strategies in behaviour change systems using the ARCS model of motivation. Behav Inf Technol 2019;38(4):319-35.

34. Almojaibel AA, Munk N, Goodfellow LT, et al. Health care practitioners' determinants of telerehabilitation acceptance. Int J Telerehabilitation 2020;12(1):43-50. 